\title{
Incorporating Active Learning into Moral Education to Develop Multiple Intelligences:
} A Qualitative Approach

\author{
Nadarajan Thambu', Harun Joko Prayitno², Gamal Abdul Nasir Zakaria ${ }^{3}$ \\ ${ }^{1}$ Faculty of Human Sciences, Universiti Pendidikan Sultan Idris, Malaysia \\ ${ }^{2}$ Teacher Training and Education Faculty, Universitas Muhammadiyah Surakarta, Indonesia \\ ${ }^{3}$ Sultan Hasanah Bolkiah Institut of Education, Universiti Brunei Darussalam, Brunei Darus- \\ salam
}

DOI: 10.23917/ijolae.v3i1.10064

Received: January 29 th 2020 . Revised: April $1^{\text {st }}, 2020$. Accepted: April $3^{\text {rd }}, 2020$

Available Online: April 20 ${ }^{\text {th }}, 2020$. Published Regularly: January $1^{\text {st }}, 2021$

\begin{abstract}
Recognizing and nurturing all the varieties of human intelligences is essential for exploring the talents of students and enabling their identification of multiple intelligences. Studies have suggested that eliciting the maximum potential of intelligences leads to students' success in their academic and future careers. The literature has shown that incorporating active learning into the teaching and learning of moral education to develop multiple intelligences is limited. Accordingly, this study aims to discover the various intelligences that exist among moral education students through the active learning method. Active learning implies that all learners are provided with time and assistance to realize their potential. In this regard, multiple intelligence theory is used as the theoretical framework for defining, understanding, developing, and estimating the various intelligences that students have. The research design for this study is the qualitative method. A total of fourteen students from two schools were chosen as research participants. Data were collected through observation, focus group interviews, and journal entries. These findings reveal that using the active learning method in moral education can develop students'verbal linguistic intelligence, logicalmathematical intelligence, musical intelligence, spatial intelligence, bodily kinesthetic intelligence, intrapersonal intelligence, interpersonal intelligence, and naturalistic intelligence. Integration and internalization of the eight intelligences into active learning holistically will shape the personality and character of students in social life.
\end{abstract}

Keywords: active learning, moral education, multiple intelligence, qualitative approach

Corresponding Author:

Nadarajan Thambu, Faculty of Human Sciences, Universiti Pendidikan Sultan Idris, Malaysia

Email:nada@fsk.upsi.edu.my

\section{Introduction}

All educators have the responsibility for creating a positive learning environment that provides learners with sufficient opportunities to practice, using the new knowledge and skills that they have gained. At the same time, educators need to cater for the different intelligences of learners (Gardner, 2008, 2011; Koksal Akyol, 2018). Meanwhile, the moral education curriculum encourages students to participate actively in the teaching and learning process. Active and interactive student participation in teaching and learning will give students the opportunity to ques- 
tion, communicate, and interact with each other while giving and sharing opinions and ideas (Carr, Palmer \& Hagel, 2015). Among the teaching and learning strategies proposed in the moral education curriculum is active learning. Hence, teachers need to design and provide learning experiences in an active learning climate to foster a variety of student intelligences (Malaysia Ministry of Education, Standard Curriculum and Assessment Document, Moral Education, Form 2, KSSM, 2016).

Active learning consists of "instructional activities involving students in doing things and thinking about what they are doing" (Bonwell \& Eison,1991, p.28). Approaches that promote active learning focus more on developing students' skills than on transmitting information to them. They also tend to place some emphasis on students' exploration of their own attitudes and values. For Freeman, et al., (2014), active learning engages students in the process of learning through activities (reading, writing, and demonstrating) or discussion and making presentations in class as opposed to listening passively to an expert. "It emphasizes higher-order thinking and often involves group work" (p.82).

The aim of the new moral education curriculum (KSSM) is to enable all learners to achieve the maximum potential of their intelligence (Nurulwahida \& Ahmad Azman, 2014). According to Gardner (1993), intelligence is "the ability to solve problems or fashion products that are of consequence in a particular cultural setting or community" (p.15). He suggested that individuals differ in their intellectual strengths and weaknesses, and a teacher or coach, to optimize the teaching and learning environment, must be able to identify and teach these abilities by using a variety of highly correlated activities (Gardner,1999). In other words, the teacher or coach should teach with a range of in- structional strategies that cover the different abilities of the students, and providing numerous varied experiences is a critical component of helping students to become morally educated individuals (Malaysia Ministry of Education, Standard Curriculum and Assessment Document, Moral Education, Form 2, KSSM, 2016).

Active learning in moral education will enable students to understand their roles and responsibilities as effective members of various social groups, such as family, school, friends, the local community, religion, and national and global groups (Azid, Yaacob, \& Abdullah, 2016). This is because active learning involves the participation of students in the process of hands-on and mind-on learning. Through this learning, pupils will be given the opportunity to develop their skills and values as well as to become a comprehensive human (Carr, Palmer \& Hagel, 2015). There are various active learning activities and teaching strategies that can be used in the teaching and learning of moral education. Among them are small group discussions or activities such as brainstorming, role play, simulations, debates, and forums (Malaysia Ministry of Education, Standard Curriculum and Assessment Document, Moral Education, Form 2, KSSM, 2016). Moral education is an important essence in shaping the character of students in the midst of today's global society (Koussouhon \& Dossoumou, 2015; Prayitno et al., 2019; Robertson, Hepburn, McLauchlan, \& Walker, 2017).

In view of the foregoing, the focus of the present study is on examining the potential of active learning in discovering the various intelligences that exist among students of Form 2 moral education classes in secondary schools. Various active learning strategies, including face-to-face instruction with learning activities and online-mediated instruc- 
tion, are actively used for helping students to develop their multiple intelligences. In this study, all the moral education lessons were conducted by applying the active learning method.

\section{Method}

a. Research Design and Data Collection

The research design for this study is the qualitative method. The reason for using the qualitative method is to gain a better understanding of the study phenomenon, as suggested by Creswell (2012). As a form of data triangulation, this study used multiple ways of obtaining qualitative data, as recommended by Bogdan and Biklen (2007). The three qualitative approaches used to collect data were classroom observation, interviews, and journal writing. The main method was focus group interviews, in which a selected group of students was interviewed to articulate their cognitive justification. Apart from that, students' journals were analysed and interpreted to understand their multiple intelligence areas. Other sources of data, such as classroom observation, were also used to investigate students' intellectual strength.

\section{b. Participants and Instrument}

A purposive approach to sampling was undertaken by the researcher (Miles \& Huberman, 1994). The choice of research informants was based on several considerations and criteria determined by the researcher himself (Richards \& Morse, 2007). The informants of the study were Form 2 students. They consisted of male and female students who were Chinese, Indian, indigenous, and Iban. A total of fourteen students (seven male and seven female) from two schools were chosen as research participants for data collection purposes. Refering to Table 1, Instruments such as a classroom observation protocol, interview protocol, and journal writing protocol were used to collect relevant data. The content validity of the instruments was assured through comments and critiques from experts in moral education and active learning pedagogy.

Table 1. Number of Participants

\begin{tabular}{cccc}
\hline School & Class & $\begin{array}{c}\text { Number of Students in } \\
\text { the Class }\end{array}$ & $\begin{array}{c}\text { Number of Students } \\
\text { that make up Focus } \\
\text { Group }\end{array}$ \\
\hline SMK Sun & 2 A \& 2B & 30 & 7 \\
SMK Moon & 2 C \& 2 D & 35 & 7 \\
\hline \multicolumn{2}{r}{ The number of students used to collect data } & 14 \\
\hline
\end{tabular}

\section{c. Data Analysis, Transcription, and} Thematic Coding

After successful data collection, the collected data were transcribed with the use of a laptop and ear piece. The transcription produced twenty pages. The coding scheme was initially guided by the research questions, which provided the main themes and key coding (Braun and Clarke, 2006). The main focus was on the students' tendency to explore and learn best in learning activities in terms of multiple intelligences. The informants' responses from the three data sources were analysed to discover their intelligence profiles. Based on the analysis, repeated comparisons and similar ideas were integrated until major themes were established for the research question. The data coding pro- 
duced eight main themes and twelve subthemes.

\section{d. Study Procedure}

The researcher used an active learning environment in moral education to implement the teaching and learning process. Each teaching unit in the Form 2 moral education textbook is planned and taught using active learning (Abdullah, Mokhtar, \& Muniyandy, 2017). The instructors use Gardner's (1993) theory as a legitimate planning framework through which to offer students a variety of learning activities. Each lesson (topic) is designed and written in the daily lesson plan, which acts as a prototype and guide to teaching for the teacher. The teachers conduct one 90-minute lesson per week. Each lesson starts with set induction steps, lesson devel- opment, class activities, assessment, and closure and reflection.

The students are involved in various activities, such as simulations, group work, acting, drawing, debates, forums, games, and songs. The teacher isolates each 'intelligence' into particular activities. The instructors use all the activities to engage and foster specific intelligences. These activities are used to enhance the learning process by broadening the content of the moral education curriculum and stimulate the learning style that is the most appropriate for each individual. They include specified intelligences in specific lessons. The teachers also integrate active teaching with learning activities using online technology tools, such as online quiz activities like Kahoot! and Quizziz. Refer to Figure 1 to view the procedure for this study.

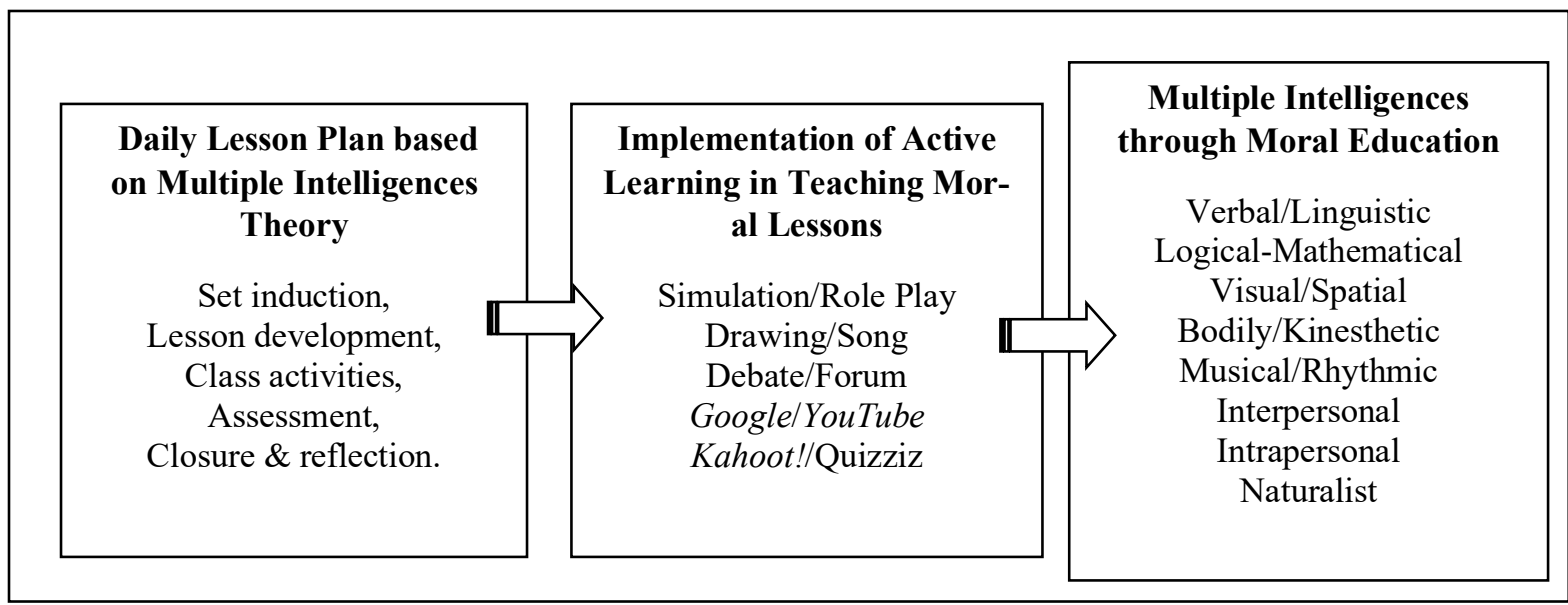

Figure 1. Procedure

\section{Result and Discussions}

Someone's intelligence and talent can be shown in various ways, their forms and expressions can make someone an expert in their field. Among these are expressions or expressions that someone uses to show their talents.

\section{a. Word Smart}

In this study, all the informants demonstrate the ability to use words effectively.
The interview results show that students can read, discuss, make presentations, write, and read about the situation and moral dilemmas given as group assignments. Students can use appropriate words when creating a poem related to friendship and the value of friendship. The language used clearly demonstrates the attitude and morality of a friend in maintaining a friendship. First, some informants explained that: 
When creating poems, we tried to use the best words for our poems to be interesting. Words like "I'm proud of being your best friend", "good luck", "thank you for understanding me", and "good heart" were used to create poems. This activity can apply the value of honesty, high concentration, and simplicity. We could also read and recite the poem well and with ease. In fact, we made innovation by making this poem in the form of a story. (Informants 2, 4, and 6).

Additionally, student journal entries and our observation show that activities such as crossword puzzles and replying to a friend's email can develop morally the verballinguistic talents among the participants. In support of the statements above on the strength of verbal-linguistic ability, informants 1,3 , and 10 expressed that:

\begin{abstract}
In replying to e-mails from friends, I was able to write passionate words for my friends who failed in the exam. I used moral words like "must be diligent", "don't give up", and "rational" to my friend. This activity applies good values. I got first place in the crossword activity. I can guess words like "honest", "trust", "sincere", and "willing to sacrifice" as having a moral character. The characteristics of a moral person are necessary to establish good relationships with others. (Informants 1, 3, and 10).
\end{abstract}

The above responses show that students can demonstrate the ability to teach, read, write, and perform morally in the Malay language. They can talk about group-based teaching topics while providing good ideas using polite, civilized, and moral language. Students are able to recite poems well, create a poem about friendships, solve crosswords correctly, and write a dialogue of casting to resolve moral conflicts based on the given situation. This finding agrees with the study by Nwagu and Nwagu (2013), which claimed that the integration of multiple activities in students' learning increases their interest in and focus on learning. Activities like games, text comprehension, and creative writing enable learning to be meaningful.

\section{b. Number Smart}

Regarding talents in logical idea and mathematical skills, the interview results show that students can think logically and solve problems. Students can also design and give reasons, find relationships, and provide critical and creative responses. Students can provide logical reasoning in solving a problem. Informants 5 and 8 expressed the following:

\begin{abstract}
Our group was required to plan and complete a model housing area that promotes unity and a neighbourhood. We first listed the reasons for unity and barriers in creating a neighbourhood spirit. Among the obstacles to creating unity in existing housing areas is the existence of walls or fences that separate one home from another. This assignment can explain the value of respect and cooperation. (informant 5).
\end{abstract}

Thereafter, we built a residential garden with no separating walls between one house and another. This facilitates the relationship between residents in a park and this facilitates unity and drives the spirit of the neighbourhood. This activity is able to explain the value of tolerance and awareness.(informant 8).

In addition, students' journal entries indicate that they can analyse a given problem before providing a logical solution. Informants 5 and 14 agreed that:

This activity really challenged my thinking. I can use empty water bottles to build a container for hydroponic plants. Before making a container for a hydroponic plant, I need to measure and cut the bottle properly. This process requires creative thinking (informant 5).

I was involved in the activities of building a solar system model that has eight planets that surround the sun. I first thought of using clay to build the eight planets. The ball of clay was so heavy and cannot be floated with a wire that is the axis of the planet. Fi- 
nally, I used a lightweight ping pong ball to float with the wire because it was light. This activity facilitates the understanding of rational values.(informant 14 ).

In support of the statement above, observation shows that students can think logically, systematically, and creatively in solving a problem. Students can engage in brainstorming to analyse a given problem. They can then record some suggestions given by colleagues, considering the causes, consequences, and ways to address those issues critically and using the logic of reason. Logical ideas and mathematical skills can be seen when they can solve a problem logically and creatively. The findings are in line with the studies by Gouws and Dicker (2011) and Nurli Fasni,Siti Fatimah and Syerli Yulanda (2017), who confirmed that learners become "cognitively active" in learning through a continual process of building, interpreting, discovering mathematical ideas, and reflective thoughts.

\section{c. Picture Smart}

Regarding talents in visual-spatial skills, the interview results show that students are able to think in the form of pictures and mental images about moral content. They are also able to learn through graphic images, mind maps, or thinking maps. All the participants can make a painting to express their thoughts and feelings morally using a computer. In addition, students are able to create threedimensional objects. The interview results show that students have the advantage of becoming aware of or conscious about visual or spatial information. They can transform and modify this information and recreate visual images with interactive multimedia. Furthermore, informants 5,7, and 8 expressed that:
We are assigned a task to produce a poster to give people the awareness of the importance of forests. The underlying value of this activity is belief in God and goodwill. My friends and me in the group first noted the importance of forests, such as rainfall, supplying oxygen and flora and fauna for habitats. After listing all of these interests, we began to figure out what things to draw, like trees, waterfalls, rivers, and plants and animals. We coloured these posters using watercolours and crayons (Infomant 5, 7, and 8).

In the light of this, the results of the journal entries and observation also indicate that students are able to exhibit visualspatial talents. They can realize or understand the concepts of vision and space well. Students can transform all abstract things into visual input forms. Informants 5 and 8 asserted that:

\begin{abstract}
I presented the moral values from the story in the form of a mind map manually and using a computer. The teaching of moral values in the story was still in the abstract form, and I transmitted the information into a more concrete mind. While building a 3D model, a safe highway in the foothills, I first determined roads in the foothills and on sloping land. Forms of landscape, such as hills, forests, swamps, and coastlines, were built in the right position and in accordance with the physical land views. The roadside trails in the foothills differ from the road bends in lowland areas. This activity facilitates the understanding of rational values (Informats 5 and 8).
\end{abstract}

Accordingly, it is understood that the majority of the informants can demonstrate visual-spatial intelligence using technological and digital tools, such as Macromedia Flash and animation projects. They can interpret messages and information from video clips and documentary films about human moral attitudes. They can translate all abstract information into more concrete forms and make it visible. In addition, students can build 3D models from given situations and draw bar graphs and pie charts to present 
information such as statistics on obesity using interactive multimedia and computer projectors. Thus, this study agrees with Denig (2004), Sultan, M.A.,et al., (2016) and Schrand (2008), that these kinds of dynamic learning can be identified as what multiple intelligence theory calls visual-spatial intelligence.

\section{d. Music Smart}

The interview results from the informants show that the students have the ability to recognize sound and have high sensitivity to rhythm and melody. Students can also write lyrics and create pop and rap songs to reveal information. In addition, students can use song melodies from other cultures (Chinese, Malay, Indian, Kadazan, and Asli) to sing songs that they have created. For example, informant 12 explained that:

\begin{abstract}
We were assigned to provide information on healthy lifestyle practices, which relate to rational values and self-esteem. We presented in a song form all the information that we gained from the Moral Text Book, like personal hygiene, exercising, health screening, and eating balanced meals. A friend of mine played guitar as background music while our group performed a song. We sang rap and pop songs. We used the melodies and rhythms of a song from Indian culture (Informant 12).
\end{abstract}

Furthermore, journal entries from the participants indicate that they have some talent in music. Informants 11 and 14 expressed that:

\footnotetext{
We were given the task of explaining the healthy heart without cigarette smoke to students. I used the heartbeat sounds, which I downloaded from YouTube as background music when I explained the importance of hearts to humans. In another task, we were assigned to describe the atmosphere of a cosy and attractive forest. While displaying the picture of the forest, we used animal sounds (animal noises), such as the chirping of birds, the noise of a
}

bunch of monkeys, tiger sounds, snakes, wind, and the sounds of a group of elephants in the jungle as background music for a better impact (Informats 11 and 14).

The views of the informants and my observation show that students can demonstrate the ability to use musical instruments. They are able to recognize various types of sounds (various animal sounds), rhythms, and song melodies. They can sing songs and present the requested information in the form of choral speaking, pop songs, and accompanied by background music, such as drums and guitar. This finding is in tandem with the work of Coban and Dubaz (2011), and McCoog (2007) which indicated that a curriculum that incorporates technology expands pupils' intelligence, such as their musical, linguistic, spatial, and intrapersonal intelligence.

\section{e. Body Smart}

The participants also show an ability to use their body to solve problems and communicate. Participants can demonstrate bodily-kinesthetic skills that relate to physical movement, body language, and how the body functions. Students have the ability to manipulate objects and use a variety of physical skills, including both gross and fine motor skills, to express their emotions and ideas to act and play games. In support of this, informants 9 and 13 reported that:

\footnotetext{
We were given a situation to reprimand friends who always come late to school. Our group played (dramatized) the situation well. In our dialogue, we used polite words and we showed proper body language to express our good intention and carry emotion towards our friend who always comes late to school. In another activity, our group was asked to present information about the importance of exercise. We demonstrated the importance of exercising by demonstrating exercise for warmth, stretching, and games such as skipping and elephant jumps. (Informants 9 and 13).
} 
In addition, students' journal notes and the researcher's observation indicate that students have bodily-kinesthetic intelligence. Informants 6 and 9 stated that:

\begin{abstract}
Me and my group produced a play titled self-responsibility and family responsibilities. We acted out ways to carry out responsibilities as parents, father, brothers, and sisters in a family. We recorded the acting and presented the recording of the acting in the classroom for viewing. This acting message was shared with friends in the classroom. In another activity, I and my team created a boria-style dance to present information about the importance of neighbourly life that will explain the value of respect. I practised for a week for this boria show. I first danced while singing. This was a new experience for me (Informants 6 and 9).
\end{abstract}

In a nutshell, this study found that students can demonstrate motor skills to express their emotions and ideas. They are very skilful in showing their physical movement and knowledge of the body. They can also translate abstract information and ideas and present them in the form of bodily movements. From their drama and dance performances, the audience can understand moral values such as accountability, affection, respect, and gratitude. This finding corroborates the studies conducted by Hui, Cheung, Wong and $\mathrm{He}$ (2011) and Koksal Akyol (2018), who concurred that drama as an active learning method enhances creativity and that the positive acquisitions of the participants in bodily-kinesthetic skills are remarkable. The kinesthetic skill of a student's body is one of the important factors in the cultivation of character and the formation of students' politeness in language (Kumar, 2017; Prayitno, H.J., 2019; Singh, Kumar, \& Atreya, 2014).

\section{f. Self-Smart}

This study found that the participants show some intrapersonal strength, namely the ability to understand the power of self. The participants demonstrate the awareness of one's own desire and abilities through the teaching and facilitating of the activities implemented. The participants like to pursue their own interests and have the ability to understand themselves, their interest, and their goal. Specifically, informant 1 expressed his views on the reality of selfknowledge and self-image, stating:

\begin{abstract}
I was assigned to write a script for our play. This activity created awareness of my strengths in that I can write a script. This activity applies value to self-esteem. After that, our group was asked to play in a forum theatre as an activity to expose the issue of a runaway child from home. I was assigned to be a Joker (moderator) for the group. This was the first time I played the role of a Joker. After taking on the role of a Joker, I realized my strength in that I could stand in front of my friends without any fear (informant 1).
\end{abstract}

Notes from the participants' journal entries also prove that they have intrapersonal intelligence. Informant 13 also reported that:

\begin{abstract}
I became one of the debaters to support the topic of religious interest as a catalyst to develop human personality. I can speak with the facts obtained from the article in the newspaper. I know the power of argument through this activity. This activity can apply the value of trust in Almighty God (Informant 13).
\end{abstract}

Informant 14 said that:

\begin{abstract}
I became a panel member in the forum activities that affected the cultural impact of hedonism on society. I looked for ideas on the Internet and gave my arguments. I am aware of my strengths in that I can process information to be discussed in the forums (Informant 14).
\end{abstract}

Thus, it is evident from this study that the respondents have intrapersonal intelligence. The observation results also show that 
they are aware of their own feelings, strengths, ideas, values, and beliefs. Those involved with active learning can process information, formulate their ideas, and reflect on their learning. Activities such as a forum theatre and forums can facilitate their understanding of the values of self-esteem and high-level courage. This finding is in congruence with the research conducted by Armstrong (2014, 2016) and Gunduz and Ozcan (2016), who found that symbolic plays, debates, storytelling, and forums help students to develop their strength, trigger their confidence, and remain as a manifestation of intrapersonal and interpersonal intelligence.

\section{g. People Smart}

In the same vein, the participants show some potential in interpersonal skills. They demonstrate the capacity for person-toperson communication and relationships. They understand the intentions, motivations, needs, and desires of others and interact with them. They are capable of working effectively with others. Informant 12 expressed as follows:

\footnotetext{
Our assignment was to hold an activity interview with community members on ways to realize the concept of a caring society. Me and my group members conducted an interview with a teacher, a retailer trader, an entrepreneur, and a politician in society. We then played the recording of the interviews to teachers and students in the classroom. This activity is capable of applying responsible values, gratefulness, and courage (Informat 12).
}

The participants' journal entries also prove their interpersonal intelligence. Informant 10, who also supports other informants on the nature of interpersonal skills, said that:
I am directly involved in the activities of raising food for orphans and poor children at one orphanage in our place. Me and my friends pick up donations from school students to purchase essential items such as biscuits, sugar, milk powder, rice, and fruits. We hand over these materials to them. This activity can apply the value of love, cooperation, and honesty among students. (Informant 10).

In line with the above statements, the observation data also show that active learning can discover the interpersonal intelligence of the participants. Out-of-class activities, such as interviews, charity projects, and helping orphans and the poor can show the participants' ability to interact successfully with others. They enjoy caring for others and learning in cooperation with others. Such activities can facilitate the understanding of moral values, such as the values of thankfulness, kindness, love, and gratefulness. This finding is synonymous with the studies conducted by Yang (2010) and Diana (2015) who found that active learning enhances students' learning in class ability to adapt, and confidence in showing their feelings and demonstrates cooperative work with others.

\section{h. Nature Smart}

Evidence from the interviews conducted shows that the participants demonstrate the ability to understand and work effectively in the natural world. Informant 4 said the following:

\footnotetext{
We have used natural materials, such as dry leaves, tree branches, tree bark, mushrooms, and rubber seeds to make souvenirs. Recyclable materials, such as plastic bottles and cans, were also used to create a pencil and flower pot. This hands-on activity can apply rational values, simplicity, and love for the environment (Informant 4).
}

Journal entries also prove the naturalistic intelligence of the participants. According to informant 3: 
Me and my group's friends were involved in taking pictures of interesting places around the school area. We captured some attractive, clean, beautiful, and green areas. We showed our collection through an LCD PowerPoint presentation to the class. This activity applies responsible values and belief in God (Informant 3).

Similarly, an informant described being nature smart in the moral class activity:

\begin{abstract}
I was involved in taking pictures of all the insects and birds around the school area. We recorded (video recording) all the movements of insects, such as ants, moths, spiders, and bugs. We also recorded crows, cockroaches, and birds. We presented this video recording in the classroom. This activity also applies moral values, such as the value of tolerance and belief in God. (Informant 5).
\end{abstract}

As a synopsis, the observation also shows that participants can demonstrate their passion about caring for Mother Nature. Minds-on, hands-on, and heart-on activities, such as capturing photos, taking video footage, creating souvenirs from natural materials, and recycling items prove their ability and sensitivity to features of the natural world. This activity facilitates the understanding of moral values, such as a belief in God, responsibility, love, and simplicity. The findings are in line with the studies by of (Azid, Yaacob, \& Abdullah, 2016), who confirmed that enrichment of activities helps learners to achieve their maximum potential. Forming character and politeness in students' language requires practice, discipline, and is done continuously (Alaba, 2015; McFarlane, 2011; Suyitno, 2019).

\section{Conclusion}

Through the active learning method in moral education, learners are free to explore and learn in a variety of ways, while educators are able to help learners understand and appreciate their strength, identifying realworld activities that will stimulate further learning. Their intellectual needs are met by constantly being challenged and frequently exercising their creativity. At the same time, their emotional needs are met by working closely with others. They develop diverse strengths, and they understand themselves better as individuals. When teachers use instructional strategies that match the intellectual strengths of individual students, they provide greater access to the moral curriculum for those students, helping them to excel in their learning. Offering a variety of activities that enhance different intelligences in moral education also helps students who are weak in certain intelligences by giving them the opportunity to improve themselves in those areas.

\section{Acknowledgements}

I wish to acknowledge the Ministry of Education, Malaysia, and Research Management \& Innovation Centre (RMIC), Sultan Idris Education University [File No: 2018-0131-106-01] for the research grant enabling this study to be carried out.

\section{References}

Alaba, A. D. S. (2015). Vision for Sustainable Development: Pragmatic Strategies of Media Political Competitive Encounter. International Journal of Language and Literature, 3(2), 134-143. https://doi.org/10.15640/ij1l.v3n2a14

Armstrong, T. (2014). You're smarter than you think: A kid's guide to multiple intelligences. Minneapolis, MN: Free Spirit Publishing.

Armstrong, T. (2016). The power of the adolescent brain: Strategies for teaching middle and high school students. Alexandria, VA: ASCD.

Bogdon, R. C.,\& Biklen, S. K. (2005). Qualitatif Research in Education: An in- 
troduction to Theory and Methods (5th ed.). Boston, MA: Allyn \& Bacon.

Bonwell, C. C., \& Eison, J. A. (1991). Active learning: Creating excitement in the classroom.Washington, DC: George Washington University Press.

Braun, V., \& Clarke, V. (2006). Using thematic analysis in psychology. Qualitative Research psychology, 3. 77-101.

Carr, R., Palmer, S., \& Hagel, P. (2015). Active learning: the importance of developing a comprehensive measure. $A c$ tive Learning in Higher Education 16, 173-186.

Coban, \& Dubaz. (2011). The relationship between active learning models in music lessons in elementary schools and multiple intelligence areas. Procedia-Social and Behavioral Sciences 28, 684-690.

Corbin, J., \& Strauss, A. (2008). Basics of qualitative research (3rd

Ed.).Thousand Oaks: Sage.

Creswell, J.W. (2012). Educational research: Planning, conducting and evaluating,quantitative and qualitative research (4th ed.). Boston: Pearson Education.

Denig, S. J. (2004). Multiple intelligences and learning styles: Two complementary dimensions. Teachers College Record 106, 96-111.

Diana. (2015). Art activity and personal intelligence: Its influence to children adaptation skill (Experiments at Hidayatullah Islamic School). Asia Pacific Journal of Multidisciplinary Research, 3(4), 133139.

Freeman, S., Eddy, S.L., McDonough, M., Smith, M.K., Okoroafor, N., Jordt, H., \& Wenderoth, M.P. (2014). Active learning increases student performance in science, engineering, and mathematics. Proceedings of the National Academy of Sciences USA 111, 8410-8415.

Gardner, H. (1993). Multiple Intelligences: The theory in practice. New York: Basic Books.
Gardner, H. (1999). Intelligences reframed: Multiple Intelligences for the 21st century. New York: Basic Books.

Gardner, H. (2008). 5 minds for the future. Boston: Harvard Business Press.

Gardner, H. (2011). Frames of mind: The theory of multiple intelligences. New York: Basic Books.

Gouws, E., \& Dicker, A-M. (2011). Teaching mathematics that addresses learners' multiple intelligences. Africa Education Review, 8(3), 568-587. DOI:10.1080/18146627.2011.618721.

Retrieve from: https://doi.org/10.1080/18146627.2011. 618721

Gunduz, N., \& Ozcan, D. (2016). The Development of Multiple Intelligence with Storytelling. International Journal of Educational Sciences, 15 (1-2), 242-251. Retrieve from: https://doi.org/10.1080/09751122.2016. 11890533

Hui,A., Cheung, P., Wong, S., \& He, M. (2011). How effective is a dramaenhanced curriculum doing to increase the creativity of preschool children and their teachers?. The Journal of Drama and Theatre Education in Asia, 2(1), 2148.

Köksal Akyol, A. (2018) Examination of the effect of drama education on multiple intelligence areas of children. Early Child Development and Care, 188(2), 157 167.

DOI: 10.1080/03004430.2016.1207635.

Koussouhon, L. A., \& Dossoumou, A. M. (2015). Political and Ideological Commitments: A Systemic Functional Linguistic and Critical Discourse Analysis of President Buhari's Inaugural Speech. International Journal of Linguistics and Communication, 3(2), 24-34. https://doi.org/10.15640/ijlc.v3n2a3

Kumar, P. (2017). Morality and Life skills : The need and importance of life skills education. International Journal of Advanced Education and Research, 2(4), 144-148. 
Majita Ahmad Sultan, Abdul Halim Masnan, Noor Aizal Akmal Rohaizad \& Mad Ithnin Salleh. (2016). Tahap pemahaman kanak-kanak terhadap konsep bentuk dalam lukisan. Jurnal Pendidikan Awal Kanak-Kanak, 5, 61-77.

Malaysia Ministry of Education (MOE). (2016). Standard Curriculum and Assessment Document, Moral Education, Form 2, KSSM. Kuala Lumpur: Curriculum Development Centre.

McCoog, I.J. (2007). Integrated Instruction:

Multiple Intelligences and Technology. The Clearing House: A Journal of Educational Strategies, 81 (1),25-28. DOI: 10.3200/TCHS.81.1.25-28. Retrieve from: https://doi.org/10.3200/TCHS.81.1.2528

McFarlane, D. (2011). Multiple intelligences: The most effective platform for global 21st Century educational and instructional methodologies. College Quarterly, 14(2), 1-8. https://doi.org/10.1097/PPO.0b013e318 233e73000130404-201109000-00018 [pii]

Miles, M.B., \& Huberman, A.M. (1994). Qualitative data analysis: A sourcebook of new methods. Baverly Hills: Sage

Nur Munirah Teoh Abdullah, Mohd. Hilmie

Mohd.Mokhtar, \& Vijayaletcmy $\mathrm{Mu}-$ niyandy. (2017). Pendidikan Moral Tingkatan 2, KSSM. Kuala Lumpur: Dewan Bahasa dan Pustaka.

Nurli Fasni, Siti Fatimah, \& Syerli Yulanda.

(2017). The implementation of multiple intelligences based teaching model to improve mathematical problem solving ability for student of junior high school. AIP Conference Proceedings 1848, 040011. Retrieve from: https://doi.org/10.1063/1.4983949

Nurulwahida \& Ahmad Azman. (2014). The effectiveness of the modular enrichment activities based on Gardner multiple intelligences and Sternberg thinking skills. Journal of Education and Practice, 5 (2), 55-62.
Nurulwahida $\mathrm{Hj}$ Azid, Aizan Yaacob \& Sarimah Shaik-Abdullah. (2016). The multiple intelligence based enrichment module on the development of human potential: Examining its impact and the views of teachers. Malaysian Journal of Learning and Instruction, 13 (2) 175200

Nwagu, E., \& Nwagu, E. (2013). Effectiveness of multiple intelligences teaching approach in drug education of pupils in Enugu State of Negeria. Journal of Education and Practice, 4 (16), 46-55.

Prayitno, H. J., Ngalim, A., Sutopo, A., Pangestu, D. W., Jamaluddin, N., \& Halim, A. (2019). Directive Politeness Act Strategy in The Discourse of Education Column in National Newspaper as The Formation of Student S ' Character In Indonesia. Humanities \& Social Sciences Reviews, 7(2), 349-362.

Prayitno, H.J., et all. (2019). Politicopragmatic Power of Positive Hospitality Comment of The Followers Account of Indonesia's President Jokowi Instagram Oriented to The Character Education in The Disruption Era 52 Indonesian Journal on Learning and Advanced Education. Indonesian Journal on Learning and Advanced Education IJOLAE, 1(2), 52-71.

https://doi.org/10.23917/ijolae.v1i2.878 5aaa.

Richards, L., \& Morse, J.M. (2007). Readme first for a user's guide to qualitative methods. London: Sage.

Robertson, L., Hepburn, L., McLauchlan, A., \& Walker, J. (2017). The humanities in the primary school-where are we and in which direction should we be heading? A perspective from Scotland. Education 3-13, 45(3), 320-331. https://doi.org/10.1080/03004279.2017. 1296920

Schrand, T. (2008). Tapping into Active Learning and Multiple Intelligences with Interactive Multimedia: A LowThreshold Classroom Approach, College Teaching, $56 \quad$ (2), 78-84. DOI: 10.3200/CTCH.56.2.78-84. Retrieve 
from:

https://doi.org/10.3200/CTCH.56.2.7. 884

Mathematics at Elementary School of Japan. International Journal of Instruction, 12(3), 781-794.

Singh, S., Kumar, R., \& Atreya, L. (2014). Yang, H. (2010). Applications of Multiple Politeness in Language of Bihar: A Case Study of Bhojpuri , Magahi, and Maithili. International Journal of Linguistics and Communication, 2(1), 97117. https://doi.org/10.1111/j.13653091.1986.tb00745.x Intelligences in Recreation Group Leadership Class. SCHOLE: A Journal of Leisure Studies and Recreation Education, 25 (1), 130-134. Retrieve from: https://doi.org/10.1080/1937156X.2010. 11949661.

Suyitno, H. (2019). Integration of Character Valuesin Teaching-Learning Process of 